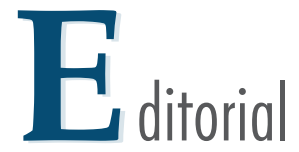

\title{
Promesas y peligros de los avances tecnológicos
}

Todos sabemos que la tecnología basada en la ciencia ha conocido un avance incesante desde los tiempos de Galileo, pero los escépticos también saben que, a diferencia de las ciencias, la tecnología es ambivalente pues, aunque en gran medida es beneficiosa, una parte de ella también es dañina. Así, por ejemplo, mientras que la ciencia nuclear ha enriquecido la civilización, la ingeniería nuclear produjo los crímenes de Hiroshima y Nagasaki y nos ha vuelto escépticos ante el futuro de la vida en la tierra. Esta ambivalencia axiológica de la tecnología es el tema de estas páginas.

Empecemos por deslindar la tecnología de la ciencia que la fundamenta.

Aunque ambas disciplinas son racionales y emplean el método científico a la hora de justificar sus principios, la ciencia se conforma con hallar nuevas verdades mientras que la tecnología se interesa, pincipalmente, por verdades de posible utilización práctica (Bunge, 1985).

Además, solamente los oscurantistas desconfían de la ciencia, y solamente los ingenuos son tecnófilos sin reparos. En efecto, tanto los irracionalistas como los partidarios del enfoque "humanista" o cualitativo de lo social son enemigos declarados del cientificismo; por otra parte, los que no son tecnófilos ni tecnófobos advierten 
la ambivalencia de la tecnología y proponen que se le ponga un bozal para protegernos de sus dentelladas.

La contribución de la ciencia básica a la tecnología ha sido exagerada unas veces y menospreciada otras. Por ejemplo, hoy sabemos que la Revolución Industrial del siglo XIX empezó en los cerebros de unos pocos artesanos y obreros calificados, no en los de ingenieros formados en universidades (Beckert, 2014). En cambio, la computadora electrónica habría sido imposible sin la física del estado sólido, aplicación de la mecánica cuántica, y sin la teoría de la computación iniciada por Alan Turing. Esto quiere decir que la tecnología posterior a la Revolución Industrial estuvo arraigada en la investigación desinteresada, la única capaz de excavar las raíces microfísicas de los fenómenos o apariencias. Pero este lado luminoso de la ciencia ocultó su lado oscuro.

El temor al lado oscuro de la tecnología no es nuevo. Ya en 1430, en plena época de los viajes de descubrimiento, cuando los navegantes chinos se embarcaban en naves diez veces más grandes que las carabelas de Colón, con tripulaciones de hasta 1500 marineros, el gobierno central del Imperio Celeste ordenó la clausura de los astilleros por temor a los posibles daños que causaría el comercio exterior a través del océano Índico: contactos con pueblos de malas costumbres y fortalecimiento excesivo del grupo de mercaderes por su contacto con el exterior.

Cuatro siglos después, durante la Revolución Industrial, la sustitución del telar manual por el mecánico tuvo consecuencias trágicas: el desempleo de miles de tejedores manuales y el surgimiento del movimiento ludista, que rechazaba la introducción y el uso de todas las máquinas modernas. Y si bien el ludismo fue reprimido con violencia, la desocupación tecnológica apenas conmovió a unos pocos. En particular, el gran poeta romántico Heinrich Heine escribió su famosa balada de "Los tejedores de Silesia". Los economistas y filósofos de la época, en cambio, no abrieron la boca. No supieron qué hacer frente a ese hecho social nuevo: un cambio progresivo que enriqueció a unos pocos y empujó a millares a la miseria.

Un siglo después, cuando el uso masivo de computadoras desalojó a los calígrafos y taquígrafos, hubo economistas que quisieron consolarnos asegurándonos que si bien era cierto que la mecanización envejecía algunos oficios, también creaba otros, de modo que al cabo de un corto período el problema de la desocupación tecnológica desaparecería. Pero esto era falso, porque un empleado que maneja 
computadoras reemplaza a otros dos atados al tintero y el dictáfono. En la actualidad aún sufrimos esta consecuencia de la automatización que empezó en fábricas y oficinas hacia 1950.

La verdad es que los avances tecnológicos causan desempleo y que hasta ahora nadie nos ha dicho qué puede hacerse para evitar esta consecuencia. Yo me atrevo a insinuar que nada podrá eludirla pero que hay una manera de salvar a los trabajadores que resultan "redundantes" al ser reemplazados por máquinas. Este remedio parcial es la sustitución de la propiedad privada por la cooperativa de producción.

En efecto, tanto las ganancias como las pérdidas se distribuyen entre los cooperantes, quienes ganan al mecanizarse parte del trabajo. En otras palabras, las pérdidas causadas por las mejoras en la producción son absorbidas por la cooperativa, que las transmuta en ganancias en la calidad de vida. En resumen,

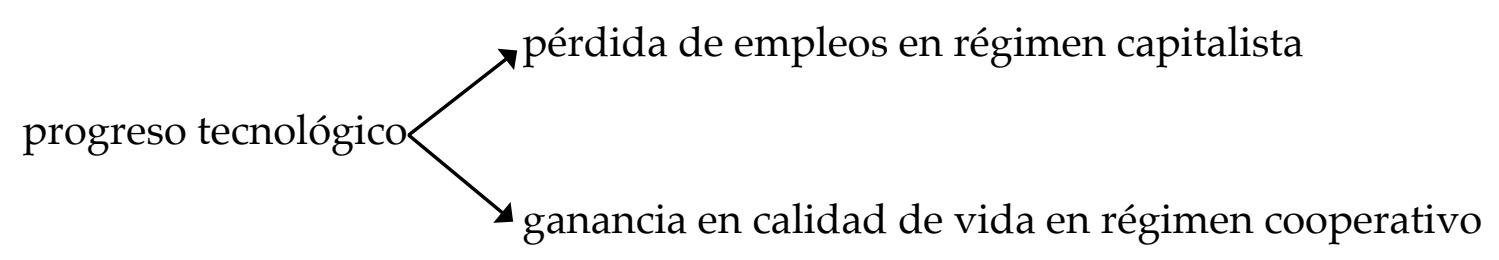

Semejante transmutación, inimaginable en una perspectiva individualista, es obvia en una perspectiva sistémica (Blanc, 1847; Bunge, 2009).

La mecanización del trabajo tiene también consecuencias médicas, algunas de las cuales son netamente desfavorables. Baste pensar en el sedentarismo y sus acompañantes, la obesidad y los trastornos cardiovasculares. Pero al menos estos asesinos silenciosos pueden controlarse con gimnasia adaptada a los horarios de trabajo. También este aspecto de la organización del trabajo puede gestionarse mejor en una cooperativa de producción que en un mercado constituido por agentes mutuamente independientes, ya que la cooperativa puede emplear consultores médicos y entrenadores.

Finalmente, echemos un vistazo al aspecto conceptual del adelanto tecnológico. El uso de computadoras permite manejar montañas de datos, potenciando el cálculo numérico y la estadística descriptiva. En particular, la computadora personal ha 
reforzado notablemente la rama computacional de las ciencias, tales como la física computacional. Pero este avance ha tenido un compañero negativo: el descuido de problemas fundacionales. En efecto, los programas de cómputo dan las teorías por sentadas, lo que lleva al dogmatismo, tan dañino tanto en las ciencias como en las humanidades (Truesdell, 1984). En particular, el culto de la computadora ha facilitado el cálculo de correlaciones estadísticas entre variables arbitrarias.

En suma, el avance en poder computacional ha sido menoscabado por un retroceso en investigación fundacional, lo que podría haberse previsto, ya que calcular es más fácil y más satisfactorio que inventar o evaluar nuevos formalismos matemáticos. Recordemos que el joven Stalin trabajó como calculista en el observatorio meteorológico de Tiflis y que pudo hacerlo porque este trabajo no requería conocimientos científicos. Este caso ilustra la diferencia entre verdades de razón y verdades de hecho, que ya había señalado Leibniz en 1704.

Mario Bunge

marucho.bunge@gmail.com

Department of Philosophy McGill University, Montreal, Canada

\section{REFERENCIAS}

Beckert, S. (2014). Empire of Cotton: A Global History. New York: Knopf Doubleday Publishing Group.

Blanc, L. (1847). Organisation du travail. Paris: au Bureau de la Société de l'industrie fraternelle.

Bunge, M. (2009). Filosofía política. Barcelona: Gedisa.

Bunge, M. (1985). Treatise on Basic Philosophy (v. 7). Dordrecht: Reidel Publishing.

Truesdell, C. (1984). An Idiot's Fugitive Essays on Science. New York: SpringerVerlag. 